\title{
Assessing the impact of nutrition education on growth indices of Iranian nomadic children: an application of a modified beliefs, attitudes, subjective-norms and enabling-factors model
}

\author{
Mousa Salehi ${ }^{1 *}$, S. M. Kimiagar ${ }^{1}$, M. Shahbazi ${ }^{2}$, Y. Mehrabi $^{1}$ and A. A. Kolahi ${ }^{1}$ \\ ${ }^{1}$ College of Nutrition Sciences, Shahid Beheshti University, West Arghavani Street, Tehran, Iran \\ ${ }^{2}$ Department of Public Health, JSU, Jackson, Mississippi, USA
}

(Received 5 March 2003 - Revised 25 November 2003 - Accepted 15 January 2004)

In order to teach suitable feeding and hygiene practices to a group of randomly selected Qashqa'i tribe families with 406 children aged 0-59 months, a culturally appropriate community-based education intervention approach was used. To assess the impact of the intervention on the study group, another group of families with 405 children were randomly selected to serve as the controls. At the beginning of the intervention programme both groups of children had access to a similar diet, consisting of cereals, beans, oil, sugar, milk and yoghurt. Baseline data, age, gender, weight, height and mean arm circumference (MAC), were obtained before the intervention. Using Hubley's behavioural change model, the components of which deal with beliefs, attitudes, subjective norms and enabling factors, the research team studied the behaviour of the family members and tried to change their nutritional behaviour. This was achieved by designing a suitable education programme to be carried out for 12 months. During the programme, families were instructed to follow different methods of food preparation and cooking practices. The final data were collected 3 months after the end of the intervention programme. The results indicated that the children in the study group gained: 1.16 (SD 1.2) kg body weight, 0.033 (SD 0.05) $\mathrm{m}$ in height, 0.0067 (SD 0.015) $\mathrm{m}$ in MAC, 0.8 (SD 1) in weight-for-age Z-score, 0.97 (SD 1.7) in height-for-age Z-score and 0.28 (SD 1.8) in weight-for-height Z-score by the end of the study. The corresponding values for the control group were 0.42 (SD 1.0), 0.0167 (SD 0.047), 0.0017 (SD 0.012), 0.35 (SD 1.1), 0.56 (SD 1.5) and 0.014 (SD 1.6) respectively and the differences were statistically significant $(P<0.05)$. These findings suggest that educational interventions involving parents and/or other family members who might play a role in the care behaviour and care resources are important in feeding the children energy- and protein-enriched, hygienic, simple and cheap foods. Such practices could improve child growth even under conditions of poverty.

Nutrition education: Malnutrition: Iranian children: Qashqa'i tribal people: BASNEF model

The Qashqa'i form approximately 500000 Turkish-speaking ethnic nomadic pastoralist tribal people, living in Fars Province, Iran. The Qashqa'i is divided into six large tribes, some smaller tribes and many sub-tribes. Despite some differences, there are customs, values, world views and practices linked through the Qashqa'i Turkish language that can be called 'Qashqa'i culture'. While some Qashqa'i have settled, most of them still practice seasonal migration and mobile schools are provided to teach their children. Schoolteachers and elders play major roles among the Qashqa'i (Shahbazi, 1998).

Of 11.6 million deaths in children $<5$ years old in lowincome countries in 1995, it has been estimated that 6.3 million $(54 \%)$ were associated with malnutrition, the majority due to mild to moderate malnutrition as opposed to severe malnutrition (Bailey et al. 1998). Furthermore, there is strong evidence that poor growth or small size is associated with impaired development (Politt et al.
1993). One study (Iranian Health Ministry, 2001) documented that $49 \%$ of rural girls and boys $<5$ years old in southern parts of Iran are malnourished, with height-forage $\mathrm{Z}$-score $(\mathrm{HAZ})<-2$. Part of the growth deficit is likely to be caused by poor diets and improper feeding practices.

In Qashqa'i tribes there are numerous obstacles to good child health, including extreme poverty, frequent natural disasters, a poorly functioning health infrastructure, poor sanitation and low literacy. As in other developing countries, Qashqa'i tribal children gain weight well within the first few months after birth, but after 6 months weight gain fails to meet international standards (Salehi $\&$ Neghab, 2001). Nearly $100 \%$ of infants born in Qashqa'i tribes are breast-fed, and breast-feeding continues through the second year of life (Bahman-Baigi, 1990). In Iran, the introduction of a variety of foods is often delayed, based on the notion that young children cannot digest foods

\footnotetext{
Abbreviations: BASNEF, beliefs, attitudes, subjective norms and enabling factors; HAZ, height-for-age Z-score; MAC, mean arm circumference; WAZ, weight-for-age Z-score; WHZ, weight-for-height Z-score.

* Corresponding author: Mr Mousa Salehi, fax +98 7117260225 , email sinasal2001@yahoo.com
} 
that are available to the family (e.g. beans) or that some foods would cause stammering, delay speech and impair intellect if introduced before 18 months of age (particularly egg and cheese). Thus, children may not receive adequate amounts of protein- and micronutrient-rich foods until 18 months of age (Rabiee \& Geissler, 1992).

Preliminary studies (Salehi \& Kalantari-Rahmani, 1999) showed that the food purchased and taken home was sufficient in amount, but the number of malnourished children in the group described earlier was nevertheless greater than in the average Iranian population. The authors looked for improper health and nutrition behaviour in those taking care of the children and tried to change them. For this purpose, they made use of the adapted behaviour change model (Hubley, 1993), which focuses on changes of knowledge, attitudes, beliefs and subjective norms in the study population. By attracting the support of influential persons in the families and in the whole tribal community, they provided the enabling factors necessary for attaining their objectives.

Exposure to education and information could enable mothers to make the best use of the resources available to them to overcome some of the difficulties (Edrisinghe \& Hettiaratchi, 1986), but whether nutrition education alone can successfully improve the diets of children suffering from extreme poverty still remains unclear. Nonetheless, from May 1999 to May 2000, Fars Province Health Centre and the Food and Nutrition Management Department conducted a nutrition education programme in forty subtribes located in Fars Province, Iran. The intention behind this project was to develop feasible messages through community-based behavioural trials and to encourage families to change their inappropriate nutritional behaviour (Iranian Health Ministry, 2002). The procedures followed were in accordance with the guidelines of the National Nutrition and Food Technology Research Institute (Iranian Health Ministry, 1996). Additional staff included a supervisor, an anthropologist and a nutritionist. It has been suggested that nutrition education programmes might be more effective if they were supported by a sound theory specifically addressing change in nutrition behaviour (Gillespie, 1987). A model for behaviour change that has the potential to be employed for nutrition education programmes is Hubley's (1993) behavioural change model, the components of which deal with beliefs, attitudes, subjective norms and enabling factors (BASNEF). The subjective norms are beliefs about the types of behaviour other influential individuals would wish the targeted subject to display. Enabling factors, including income, housing, water supply and food production, must also be available so that the intention leads to a change in behaviour (Table 1).

According to this model, individual beliefs about the consequences of certain behaviours and the value placed upon each consequence lead to personal attitudes or judgements. These attitudes, combined with the subjective norms of the community and intersectoral enabling factors, contribute to behavioural intention. According to the BASNEF model, the starting point is the individual person's behaviour. Nonetheless, an understanding of the influences on behaviour can lead to intervention that extends beyond the individuals. That is, it addresses programmes at the family, community and national levels: it involves educational, social, economic and political changes. In addition, it attempts to explain how people intentionally change their behaviour, when such changes take place, what tools changers use specifically and what indicators can be used to predict change success.

For educating and changing the behaviour of the tribal people recruited in the present study, the authors were not able to use common approaches and existing study sources. Normally, models of health education focusing on behavioural studies and the facilities necessary for behavioural change whould have been used. The BASNEF model seemed appropriate for the present purpose. This project tried to present the concepts of growth and development from a new perspective and to find an approach for measuring and monitoring care resources and care behaviours. Consequently, the educational model was reviewed and adapted to benefit the care donors (mothers) and the care receivers (children $<5$ years of age). Finally, attention was paid to observing and reporting developments in the care resources and care behaviours. Proposals were made for further development of the provision of care in this group.

Table 1. Behaviour change model (adapted from Hubley, 1993; McKee, 2002)

\begin{tabular}{|c|c|c|c|}
\hline Aspects & Influences & Actions needed & Questions to ask \\
\hline Knowledge & Programme planning, books, educators & $\begin{array}{l}\text { Health and nutrition classes } \\
\text { for influential people, educated } \\
\text { girls and tribal teachers }\end{array}$ & Questionnaire no. 2 \\
\hline Beliefs, attitudes (individual) & $\begin{array}{l}\text { Culture, values, traditions, education, } \\
\text { experiences }\end{array}$ & $\begin{array}{l}\text { Building on positive and } \\
\text { neutral aspects in communication } \\
\text { to modify beliefs and } \\
\text { values }\end{array}$ & Questionnaire no. 3 \\
\hline Subjective norms (community) & $\begin{array}{l}\text { Family, community, influential people, } \\
\text { educated girls and tribal } \\
\text { teachers }\end{array}$ & $\begin{array}{l}\text { Communication directed at persons } \\
\text { of influence in family } \\
\text { and community }\end{array}$ & $\begin{array}{l}\text { What interest do other } \\
\text { people in the tribe } \\
\text { have in health and } \\
\text { nutrition behaviours? }\end{array}$ \\
\hline Enabling factors (inter-sectoral) & $\begin{array}{l}\text { Appropriateness of safe water, } \\
\text { status of women, environmental } \\
\text { conditions, easy methods for } \\
\text { food preparation }\end{array}$ & $\begin{array}{l}\text { Capacity building activities in } \\
\text { community, skill training, gaining } \\
\text { support from influential people }\end{array}$ & $\begin{array}{l}\text { What do you need } \\
\text { to have good health } \\
\text { and nutrition? }\end{array}$ \\
\hline
\end{tabular}




\section{Materials and methods}

\section{Intervention design}

Given the nature of the target population (mostly illiterate, with influential customs and cultural practices), an adapted version of Hubley's (1993) model seemed necessary (Table 1), i.e. to alter the subjective norms of these indigenous people, it was essential to involve influential members of their families and community.

The influential people are those deeply respected by their tribal families and members. With their prestige, leadership and close contact with the community, the influential people were effective in establishing close contact between the authors and the tribal people. Having had numerous sessions with them, the authors managed to obtain their full support to their educational programme. Some of the tribal teachers were also among the influential persons. The influential people were then asked to help the researchers to recruit the volunteer tribal girls, who completed at least primary school education.

The particular nature of our target population (Table 2) made it essential for us to transfer some basic health and nutritional information to the people under study. To achieve this, we sought the educational assistance of the literate daughters. The instructions were first given to the daughters, serving as our first target population; they assisted the researchers in disseminating the information

Table 2. Characteristics of sample children and their families

\begin{tabular}{|c|c|c|c|c|}
\hline & \multicolumn{2}{|c|}{$\begin{array}{l}\text { Test group } \\
(n \text { 406) }\end{array}$} & \multicolumn{2}{|c|}{$\begin{array}{l}\text { Control group } \\
(n \text { 405) }\end{array}$} \\
\hline & Mean & $\overline{S D}$ & Mean & $\overline{S D}$ \\
\hline \multicolumn{5}{|l|}{ Children's baseline variables } \\
\hline Age(months) & $30 \cdot 2$ & 17 & $30 \cdot 4$ & $16 \cdot 7$ \\
\hline WAZ & -1.4 & 0.8 & -0.97 & 0.8 \\
\hline HAZ & $-2 \cdot 1$ & 1.3 & -1.6 & $1 \cdot 1$ \\
\hline WHZ & -0.02 & 1.4 & 0.16 & 1.2 \\
\hline Mother's age (years) & 23.4 & $5 \cdot 3$ & 24.8 & 5.9 \\
\hline Household members $(n)$ & $8 \cdot 3$ & 3.5 & 7.9 & 3.4 \\
\hline Children $(n)$ & 4.2 & 1.7 & 4 & 1.8 \\
\hline \multicolumn{5}{|l|}{ Mother's education (\%) } \\
\hline None & 61 & & 59 & \\
\hline Completed primary & 27 & & 28 & \\
\hline Completed secondary & 12 & & 13 & \\
\hline Non-hygienic latrines (\%) & 93 & & 90 & \\
\hline \multicolumn{5}{|l|}{ Father's major occupation (\%) } \\
\hline Shepherd & 88 & & 93 & \\
\hline Agricultural/skilled labour & 10 & & 6 & \\
\hline Other & 2 & & 1 & \\
\hline \multicolumn{5}{|l|}{ Tent type (\%) } \\
\hline Black & 69 & & 75 & \\
\hline White & 31 & & 25 & \\
\hline \multicolumn{5}{|l|}{ Animals $(n)$} \\
\hline Sheep & 56 & 23 & 61 & 31 \\
\hline Goats & 78 & 29 & 82 & 38 \\
\hline \multicolumn{5}{|l|}{ Source of drinking water (\%) } \\
\hline Spring & 13 & & 10 & \\
\hline Well & 19 & & 22 & \\
\hline Stream & 49 & & 56 & \\
\hline Pond & 15 & & 12 & \\
\hline Other & 4 & & - & \\
\hline
\end{tabular}

WAZ, weight-for-age Z-score, HAZ, height-for-age Z-score; WHZ, weight-forheight Z-score. to the care donors (the tribal women). In this connection, Hubley's (1993) model had to be modified to include a new aspect called 'knowledge'.

The volunteers were then brought together and trained in environmental health, personal hygiene, ways of obtaining clean drinking water, effective use of vaccination programmes, appropriate use of the child growth chart, daily intake of all food groups as stated in the food pyramid, appropriate food preparation and essential foods during pregnancy and lactation. The training took place in three phases: the first phase included a 2-week training on these subjects; the second, provision of feedback in the field; the third was a retraining programme that addressed most of the field problems experienced by the volunteers. These female volunteers assisted in carrying out the intervention programme. For details of the education programme steps and content, see Appendix.

\section{Sampling}

The authors randomly selected 960 families in forty-eight sub-tribes of the Qashqa' $i$ and divided them into test and control groups. After an initial screening, 811 children (406 test and 405 control subjects) were included in the sample. These children ranged in age from 0 to 59 months. The homes of the control families were located $5-10 \mathrm{~h}$ walk away from the test families.

\section{Questionnaires}

Questionnaires were used for evaluating the tribal parents' knowledge and attitudes toward the project. The questions were put in the form of multiple choice and the choices made based on focus-group discussion. The validity and reliability of these questionnaires were evaluated by using the split-half correlation coefficient method. According to this method, the questions were first used for the whole study group, after which the group was divided into two halves. The questions with odd numbers were then written in a separate questionnaire and used for the first subgroup, while those with even numbers were written in another separate questionnaire and used for the second subgroup. The correlation coefficient of both questionnaires showed the validity of the two separate questionnaires. For calculating the validity coefficient of the complete questionnaire, the correlation coefficients of both halves were used in the Spearman-Brown formula. The validity of the complete questionnaire having been confirmed, this questionnaire was filled out by the female volunteers after asking the caregivers.

\section{Evaluating and scoring the mothers' knowledge and attitudes}

The parents of the children were examined by arranging face-to-face interviews. Fathers did not participate in such sessions eagerly, while mothers were encouraged by their educated daughters to participate in the study to answer our questions. The adjusted marks in knowledge examinations and Likert tests were analysed by the nonparametric Mann-Whitney test. 


\section{Data collection}

Baseline dietary and socio-economic data were collected from all sample households, and anthropometric, dietary and child-morbidity data were collected monthly except for 2 months during autumn and spring migrations. Weight was measured with a portable SECA childmother scale ( ), height with a SECA 208 meter, and mean arm circumference (MAC) with a meter tape. To record three $24 \mathrm{~h}$ recalls for each child, the volume of the vessels commonly used by the tribe members and the amount of the food $(\mathrm{g})$ that could be served in these vessels were measured. These values were then used to estimate each child's food consumption (based on the National Nutrition and Food Technology Research Institute's food composition tables; Movahedi, 2000). Child morbidity data consisted of the mother's monthly recall of the type of illness and the approximate number of days during the month in which the child was sick.

\section{Data analysis and variable construction}

Data analysis was carried out with EPI-INFO and SPSS for windows (version 10.1; SPSS Inc., Cary, NC, USA). Z-scores for HAZ, weight-for-age (WAZ) and weight-forheight (WHZ) were calculated with EPI-INFO using the National Center for Health Statistics data from the USA (1985) as a reference (Reinhard \& Kramer, 1999).

The weight and height measurements of the children were expressed in terms of Z- scores, based on the standard deviation above or below the median reference value for a person of a given age.

The impact of each education programme was evaluated based on changes pre- and post-intervention, dietary adequacy and nutritional status of children. To measure the status of the children, the following indicators were applied (Reinhard \& Kramer, 1999):

$$
\begin{aligned}
\text { stunting }= & \mathrm{HAZ}<-2 \mathrm{sD} \text { of reference population } \\
& \text { indicator for long term nutritional } \\
& \text { deprivation; } \\
\text { wasting }= & \mathrm{WHZ}<-2 \mathrm{SD} \text { of reference population } \\
& \text { indicator for acute malnutrition; }
\end{aligned}
$$

underweight $=\mathrm{WAZ}<-2 \mathrm{SD}$ of reference population commonly used for national and regional statistics.

The baseline anthropometric variables were taken as the first measurement available during the recruitment in July and August 2001. For the final variables, the last measurement available during the month of August 2002 was used. The children's intakes of energy, protein and fat were computed by calculating the mean values for the three $24 \mathrm{~h}$ recalls.

For children aged 12-59 months, the estimated energy daily requirement was $40 \mathrm{~kJ}(105 \mathrm{kcal}) / \mathrm{kg}$ body weight. The safe protein requirement, which ranged from $2.3 \mathrm{~g} / \mathrm{kg}$ for children aged $1-24$ months to $1.7 \mathrm{~g} / \mathrm{kg}$ for children

aged 25-59 months was calculated. The protein content of non-animal foods was adjusted for quality, assuming $85 \%$ digestibility and $75 \%$ amino acid score (Food and Agriculture Organization/World Health Organization/ United Nations University, 1985).

Socio-economic indicators, collected at baseline, included education and mean number of household members, occupation, tent type, number of animals (sheep and goats), source of drinking water, latrine type and level of education, created for each household (Table 2).

\section{Statistical methods}

The impact of the education intervention was determined by examining the differences of continuous variables in the baseline and endpoint observations. Mean values for anthropometric data in treated and control groups were compared by Student's $t$ test. Mean values of anthropometric data for treated and control groups were compared by linear regression. The Mann-Whitney test was used to determine group differences in knowledge and attitude scores. Changes in the proportion of malnourished children from pre- to post-intervention were analysed using the test of proportions ( $z$ test) for each group. The statistical significance was $P<0.05$.

\section{Results}

The percentage decreases in the number of malnourished children in the test and control groups are presented in Fig. 1. Test children with $\mathrm{WAZ}<-2, \mathrm{HAZ}<-2$ and WHZ $<-2$ had $17.7,36.5$ and $3.2 \%$ decreases respectively. However, the corresponding values for the control group were $5.5,19.0$ and $1.5 \%$ respectively and the differences were statistically significant $(P<0.05)$. Similar observations were made for weight-for-age, weight-forheight and height-for-age percentiles. The results are not shown as there was a significant correlation (bivariate

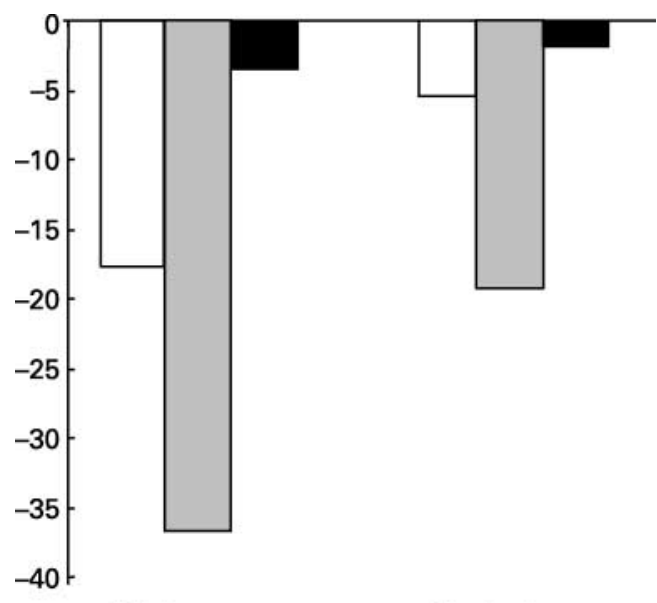

Test group

Control group

Fig. 1. Decrease in incidence of malnutrition (\%) in children in test and control groups. $\square$, Weight-for-age Z-score $<-2$; $\square$, height-forage Z-score $<-2$; $\mathbf{\square}$, weight-for-height Z-score $<-2$. For details of subjects and procedures, see Table 2 and p. 781 . 
correlation, $P<0.01)$ between these variables and the aforementioned variables.

Table 3 shows the mean differences for WAZ, HAZ, WHZ and MAC for test and control children before and after nutrition education. The differences were statistically significant $(P<0 \cdot 05)$.

Table 4 shows the improvement of the knowledge and attitudes scores for the test and control mothers before and after the education intervention programme. Test mothers gained significantly $(P<0.05)$ better values than controls.

Table 5 illustrates the cooperation of families with the programme (data gathering). The test group ranked better values than controls for cooperation, and the differences were statistically significant $(P<0 \cdot 05)$.

The correlation coefficients between knowledge and attitude $v$. anthropometric variables were analysed by linear regression. There was no strong correlation between weight and height changes $v$. knowledge $(r 0.08, r 0.13$ respectively), but there was a strong correlation between the treated children's weight gains and growth $v$. their mothers' attitudes (Likert test, $r$ 0.50, $r$ 0.48 respectively; results not shown).

As the educational programmes made mothers aware of the shortcomings in their own diets, their nutritional status could have been improved at the end of the project, since the addition of legumes and vegetables to the diet is possible even in conditions of poverty.

\section{Dietary adequacy}

Tables 6 and 7 summarize the adequacy of energy in the children's diet relative to ideal requirements at the beginning and end of the study.

At baseline, the families of the test and control children consumed their regular diets, which were similar (Table 6). During the study period, however, the families of the treated children, who were instructed about complementary foods and better ways of preparing their diet, discontinued consuming their regular diet (Table 7). The families in the test group learned how to make soup, using cereals, beans and vegetables, and to make lentil porridge. They also paid

Table 3. Effect of nutrition education on weight-for-age, height-for-age and weight-for-height Z-scores and mid-upper arm circumference in children*

(Mean values and standard deviations)

\begin{tabular}{|c|c|c|c|c|c|c|c|c|c|c|c|c|c|c|}
\hline \multirow{4}{*}{$\begin{array}{l}\text { Variables Groups } \\
\text { Test }(n \text { 406) } \\
\text { Control }(n \text { 405) }\end{array}$} & \multicolumn{2}{|c|}{ Age (months) } & \multicolumn{2}{|c|}{ Weight (kg) } & \multicolumn{2}{|c|}{ Height (m) } & \multicolumn{2}{|c|}{ MAC (m) } & \multirow{2}{*}{\multicolumn{2}{|c|}{ WAZ }} & \multirow{2}{*}{\multicolumn{2}{|c|}{$\mathrm{HAZ}$}} & \multirow{2}{*}{\multicolumn{2}{|c|}{ WHZ }} \\
\hline & \multirow{2}{*}{$\frac{\text { Mean }}{0.45}$} & \multirow{2}{*}{$\frac{S D}{0.7}$} & \multirow{2}{*}{$\frac{\text { Mean }}{1 \cdot 16}$} & \multirow{2}{*}{$\frac{S D}{1 \cdot 2}$} & \multirow{3}{*}{$\begin{array}{l}\text { Mean } \\
0.033 \\
0.0167\end{array}$} & \multirow{2}{*}{$\frac{S D}{0.053}$} & \multirow{3}{*}{$\begin{array}{l}\text { Mean } \\
0.0067 \\
0.0017\end{array}$} & \multirow{2}{*}{$\frac{S D}{0.015}$} & & & & & & \\
\hline & & & & & & & & & 0.8 & 1.0 & 0.97 & 1.7 & 0.28 & 1.8 \\
\hline & & 0.8 & 0.42 & 1.3 & & 0.047 & & 0.012 & 0.35 & $1 \cdot 1$ & 0.56 & 1.5 & 0.014 & 1.6 \\
\hline $\begin{array}{l}\text { Statistical significance } \\
\text { of effect ( } t \text { test) } P\end{array}$ & \multicolumn{2}{|c|}{0.59} & \multicolumn{2}{|c|}{0.001} & \multicolumn{2}{|c|}{0.001} & \multicolumn{2}{|c|}{0.001} & \multicolumn{2}{|c|}{0.001} & \multicolumn{2}{|c|}{0.008} & \multicolumn{2}{|c|}{0.02} \\
\hline
\end{tabular}

MAC, mean arm circumference; WAZ, weight-for-age Z-score; HAZ, height-for-age Z-score; WHZ, weight-for-height Z-score.

${ }^{*}$ For details of subjects and procedures, see Table 2 and p. 781.

Table 4. Mother's knowledge and attitude scores before and after education in test group $\dagger$ (Mean values and standard deviations)

\begin{tabular}{|c|c|c|c|c|c|c|c|c|}
\hline \multirow{2}{*}{ Groups } & \multirow{2}{*}{ Steps } & \multirow{2}{*}{$n$} & \multicolumn{2}{|c|}{ Age (years) } & \multicolumn{2}{|c|}{ Knowledge } & \multicolumn{2}{|c|}{ Attitude } \\
\hline & & & Mean & SD & Mean & SD & Mean & SD \\
\hline \multirow[t]{3}{*}{ Tests } & Before & 504 & 23.4 & $5 \cdot 3$ & $62 \cdot 3$ & 5.9 & 41.5 & 8.4 \\
\hline & After & 481 & 24.5 & 4.9 & 79.6 & 4.7 & 74.7 & $12 \cdot 3$ \\
\hline & Difference & - & $1 \cdot 1$ & $2 \cdot 3$ & $17 \cdot 3^{\star}$ & 7.5 & $33 \cdot 2^{*}$ & $13 \cdot 2$ \\
\hline \multirow[t]{3}{*}{ Controls } & Before & 411 & 24.8 & $5 \cdot 9$ & $64 \cdot 2$ & $5 \cdot 6$ & 42.5 & 8.7 \\
\hline & After & 388 & $26 \cdot 1$ & 5.4 & $66 \cdot 8$ & 4.7 & $49 \cdot 4$ & 3.2 \\
\hline & Difference & - & 1.3 & $2 \cdot 3$ & 2.59 & 7.5 & 6.83 & 9.2 \\
\hline
\end{tabular}

Mean values were significantly different from the corresponding control values (Mann-Whitney test): ${ }^{\star} P<0.05$

†For details of subjects and procedures, see Table 2 and p. 781.

Table 5. Degree of families' cooperation with the education programme*

\begin{tabular}{lcccc}
\hline Cooperation ranking of influential people & Good $(\%)$ & Moderate $(\%)$ & Weak (\%) & Total (\%) \\
\hline Test group $(n$ 490) & 69 & 17 & 15 & 100 \\
Control group $(n$ 470) & 34 & 27 & 39 & 100 \\
Statistical significance of effect $(z$ test): $P$ & 0.0001 & 0.001 & 0.0001 & - \\
\hline
\end{tabular}

${ }^{*}$ For details of subjects and procedures, see Table 2 and p. 781 
Table 6. Quantity and contents of the regular diet among the control and test children at the beginning of programme* (Mean values and standard deviations)

\begin{tabular}{|c|c|c|c|c|c|c|c|c|}
\hline \multirow[b]{2}{*}{ Food } & \multicolumn{2}{|c|}{ Quantity (g) } & \multicolumn{2}{|c|}{ Energy (kJ) } & \multicolumn{2}{|c|}{ Animal protein $(\mathrm{g})$} & \multicolumn{2}{|c|}{ Plant protein (g) } \\
\hline & Mean & SD & Mean & SD & Mean & SD & Mean & SD \\
\hline Wheat flour & 200 & $47 \cdot 7$ & 2898 & 694 & & & 25 & 5.8 \\
\hline Lentil flour & \multirow{2}{*}{\multicolumn{2}{|c|}{ - }} & \multirow{2}{*}{\multicolumn{2}{|c|}{-}} & \multicolumn{2}{|c|}{-} & & \\
\hline Bean & & & & & & & & \\
\hline Meat & 50 & 62.5 & 1234 & 1539 & 6 & 7.5 & & \\
\hline Milk & 50 & $13 \cdot 2$ & 142 & 37 & 1.7 & 0.43 & & \\
\hline Egg & 16 & 15 & 105 & 99 & 2 & 1.9 & & \\
\hline Oil & 20 & 7 & 752 & 263 & & & & \\
\hline Sugar & 30 & $8 \cdot 6$ & 502 & 145 & & & & \\
\hline Fresh vegetables & \multicolumn{2}{|c|}{-} & \multicolumn{2}{|c|}{-} & & & & \\
\hline Dried vegetables & \multirow{2}{*}{\multicolumn{2}{|c|}{-}} & \multirow{2}{*}{\multicolumn{2}{|c|}{-}} & & & & \\
\hline Seasonal fruit & & & & & & & & \\
\hline Total & & & 5646 & 1397 & $9 \cdot 7$ & 6.5 & 25 & 5.8 \\
\hline Ideal amount & & & & & & & & \\
\hline
\end{tabular}

${ }^{*}$ For details of subjects and procedures, see Table 2 and p. 781.

Table 7. Quantity and contents of the final food pattern among the test children at the end of programme* (Mean values and standard deviations)

\begin{tabular}{|c|c|c|c|c|c|c|c|c|}
\hline Food & Mean & SD & Mean & SD & Mean & SD & Mean & SD \\
\hline Lentil flour & 20 & 3.6 & 255 & 47 & & & $3 \cdot 8$ & 0.72 \\
\hline Bean & 20 & $2 \cdot 6$ & 83 & 212.9 & & & $1 \cdot 6$ & 0.24 \\
\hline Meat & 50 & 16 & 1234 & 395 & 6 & 1.97 & & \\
\hline Oil & 20 & 2.6 & 752 & 99 & & & & \\
\hline Sugar & 15 & $5 \cdot 3$ & 251 & 88 & & & & \\
\hline Fresh vegetables & 30 & $16 \cdot 5$ & 17 & 9 & & & 1.5 & 0.8 \\
\hline Dried vegetables & 10 & $8 \cdot 7$ & 25 & 22 & & & 2.5 & $2 \cdot 2$ \\
\hline Seasonal fruit & 100 & 46 & 33 & 18 & & & & \\
\hline
\end{tabular}

${ }^{*}$ For details of subjects and procedures, see Table 2 and p. 781.

more attention to eating breakfast. Consequently, their children were encouraged to eat more than before, and their diets were enriched without increasing the cost of their foods. Thus, energy and protein contents as well as the contents of other necessary nutrients were increased in the diets of the test group children, enhancing the quality of their diets, as illustrated in Table 7. At the end of the study, the treated children consumed $5580 \mathrm{~kJ}(1335 \mathrm{kcal})$ and $45 \mathrm{~g}$ protein and the control children $5650 \mathrm{~kJ}$ $(1350 \mathrm{kcal})$ and $35 \mathrm{~g}$ protein. The energy in the diets of control group children was greater than in the test group (NS), but some of this energy was wasted during improper food preparation and cooking. The percentage of good quality protein (i.e. from animal rather than plant sources) in the diet of the test group at the end of the study was significantly greater than that of control group (at baseline) $(P<0 \cdot 05)$. Similarly, a greater percentage of treated children consumed foods from all food groups at the end of the study. The greatest difference in the diet of the test group as compared with the control group was the quality of the breakfast. Control children continued to eat their regular breakfast (bread and tea), whereas children in the test group ate cereals, beans, butter, eggs, vegetables and seasonal fruits for breakfast.

\section{Discussion}

Data on cultural beliefs related to caregiving at different stages in the life of an infant are often qualitative, rather than quantitative, in their approach. However, such qualitative data can be invaluable before embarking on a large scale survey from several points of view: assessing the socio-cultural causes of, and reactions to, malnutrition, infant feeding behaviours that are unique to certain cultures and beliefs, and practices relating to lactation. The factors that influence the quality of care (such as beliefs with regard to breast-feeding, infant feeding and infant growth) are expected to emerge from this discussion.

In a number of developing societies, breast-feeding is a universal practice that is initiated soon after birth (Almedom, 1991a; Cominsky et al. 1993; Harrison et al. 1993). In other cultures, particularly in the Indian culture 
and in parts of south-east Asia, there is a strong belief that colostrum is highly undesirable: pre-lacteal feeds of sweetened water, goats' milk or diluted cows' milk are commonly given in the first $2-3 \mathrm{~d}$ postpartum (Reissland \& Burghart, 1988).

Beliefs about appropriate time of initiation of complementary feeding varies across cultures, with the earliest incidence of complementary feeding seen in Indonesia (Launer \& Habicht, 1989; Harrison \& Jerome, 1992; S Kardjati, unpublished results).

The results of the present study suggest that a culturally appropriate nutrition education programme based on communication theory can change the attitudes and beliefs of caregivers and child-feeding practices, thereby improving child growth.

In the children in the test group, increased consumption of hygienically prepared, protein-rich weaning foods, introduced after the age of 6 months, not only helped to prevent further deviation from reference growth standards, but even enhanced growth (even though the supplement contained little meat). Despite the adequate and similar amounts of energy eaten in both groups at baseline, the growth of the children was not satisfactory. However, with the addition of eggs, legumes and vegetables to the diet of the children in the test group, there was a significant improvement of growth in this group as compared with the control group. The nutrition status of mothers also improved under conditions of poverty, due to educational programmes designed to enhance their nutritional awareness.

Our findings suggest that in poor communities such as the villages and tribes of Fars Province, educating the population in good hygiene and nutrition practices may improve children's growth to some extent, but possibly not to levels corresponding to international standards. This could be achieved only if the socio-economic conditions are improved and the families receive financial support.

The size and nature of effects on growth observed in the present study (Table 3) are similar to findings from other countries where nutrition education was conducted without using other interventions (Berga, 1987; US Agency for International Development, 1988). A follow-up evaluation in Indonesia 1 year after the implementation of a nutrition education programme, for instance, found that the children studied grew better than controls between 5 and 24 months of age (the test children were $1 \mathrm{~kg}(0.5 \mathrm{SD})$ heavier or greater in weight and length than the control children (Berga, 1987). However, there was no positive association for length-for-age in Indonesia (Zeitlin et al. 1984) and Upper Volta (Zeitlin, 1981). Although the MAC values for control and treated groups were not significantly different at the beginning of the study, the difference reached statistical significance at the end of study. However, MAC was not strongly related to WAZ. Nutrition intervention in stunted-child populations with normal or high weight-for-height, for example supplementation studies at the Institute of Nutrition of Central America and Panama have found no impact on wasting indicators (WHZ, MAC), but a major impact on stunting (Sahn et al. 1981). At the end of the present study the percentage of the children $<5$ years of age who were underweight, stunted and wasted was lower than that in Tamil and Muslim children in Sri Lanka (Reinhard \& Kramer, 1999). These findings suggest that the intervention

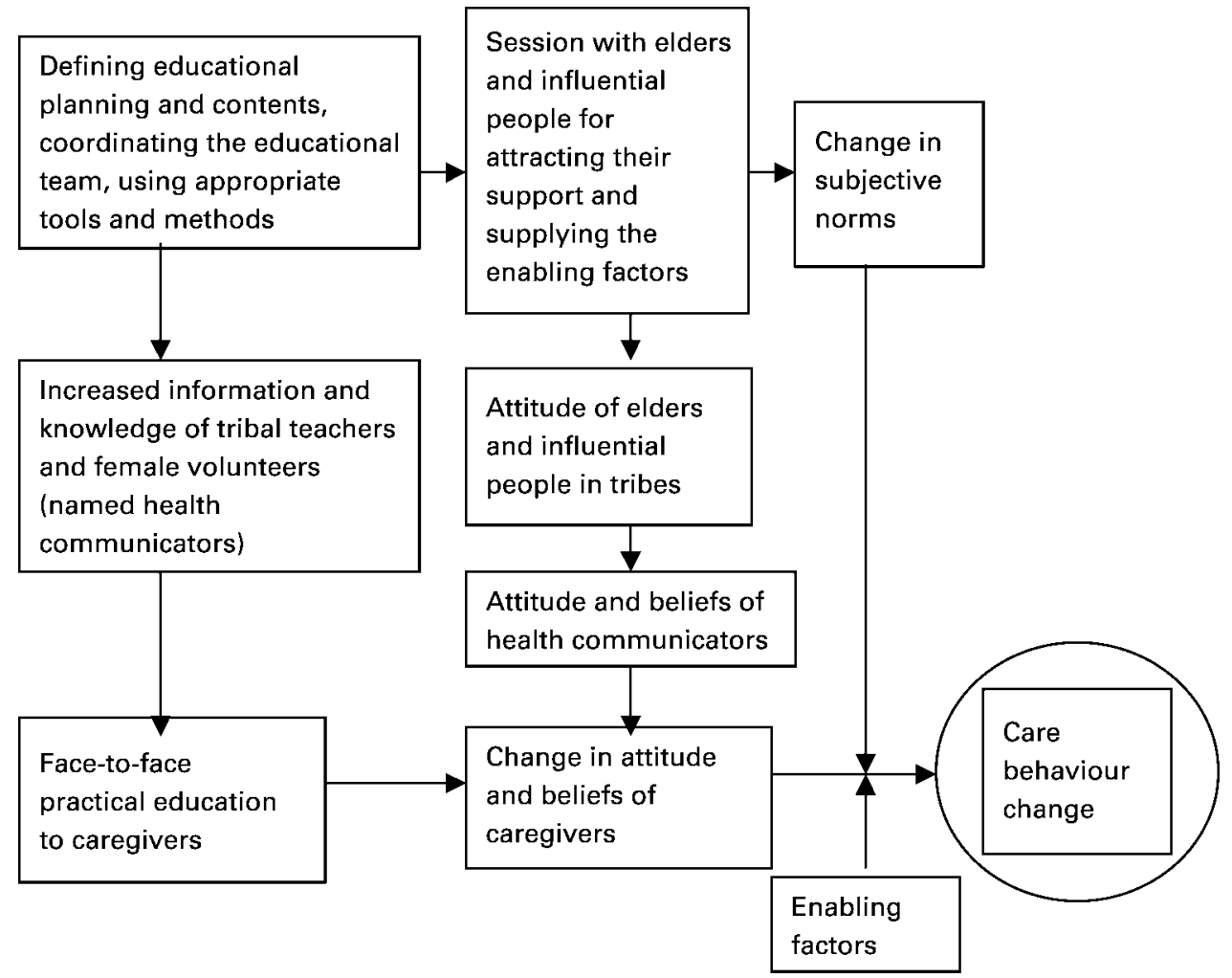

Fig. 2. Proposed framework for education programme resulting in care behaviour change among the Iranian tribes people. 
successfully encouraged families to give their children more food, regarding both volume and variety.

At the beginning of the education programme, the authors observed that the tribal women were unwilling to change their customs and dietary habits. The authors, therefore, first contacted influential people, tribal teachers and the educated daughters, instructing them about the necessity of changing food habits to achieve better health and growth of their children. The influential people and educated daughters in turn took care that the instructions given by the research team concerning the preparation of soup and the increased use of eggs, vegetables and legumes were carried out and the matter taken seriously.

Therefore, first the literate daughters were taught; these then helped the authors to maintain good communication with the parents of the children under treatment during the study. The higher values obtained by the test group for their degree of cooperation with the education programme (Table 5) shows the role of influential people ( $n$ 33) in the test group and $(n 7)$ in the control group. The authors devised communication programmes to modify beliefs and food habits of families, established communication with influential people in the family and community, and made plans to improve the provision of sanitation and the situation of women. In addition, skill enhancement among Qashqa'i sub-tribes in the study population was targeted.

\section{Conclusion}

The present project was designed to develop and test nutritional messages with the potential for behaviour change and for a positive impact on child health, given the many existing constraints dominating a tribal life. The study was carried out under conditions of poor growth and high mortality of domestic animals due to lasting drought and water shortages. The observed findings are interesting, because under the prevailing conditions, education in food preparation and complementary foods proved to be especially important and had a significant impact on the growth of the impoverished children. The results suggest that if proper messages are marketed through appropriate channels, changes in child-feeding practices resulting in improved child growth are possible. Despite their poverty, families should be encouraged to feed hygienic and cheap energy- and protein-enriched foods, as expensive practices are not likely to achieve sustained compliance. A proposed framework to convey such a nutrition message successfully is presented in Fig. 2.

\section{References}

Almedom AM (1991a) Infant feeding in urban low-income households in Ethiopia, 1, the weaning process. Ecol Food Nutr 25, 97-109.

Bahman-Baigi M (1990) Habits and Customs in Fars Tribes. Tehran: AZAR Publishing Company.

Bailey K, de Onis M \& Blossner M (1998) Protein-Energy Malnutrition, Vol. 8. The Global Burden of Disease and Injury Series. Cambridge, MA: Harvard University Press.

Berga A (1987) Malnutrition: What Can Be Done? A Lesson
From the World Bank. Baltimore, MD: Johns Hopkins University Press.

Cominsky S, Mahloyi M \& Ewbank D (1993) Child feeding practices in a rural area of Zimbabwe. Soc Sci Med 36, 937-947.

Edrisinghe N \& Hettiaratchi E (1986) Child Nutrition and its Determinants, Including Government Transfers and Intrafamilial Food Allocations. Washington, DC: Public Policy Research Institute.

Food and Agriculture Organization/World Health Organization/ United Nations University (1985) Energy and Protein Requirements. Joint Expert Consulation WHO Teach REPSE 724, pp. 71-130, pp. 140-150. Geneva: WHO.

Gillespie AH (1987) Communication theories as a basis for nutrition education. $J$ Am Diet Assoc 87, S44-S52.

Harrison G, Zaghloul SS, Galal OM \& Gabr A (1993) Breastfeeding and weaning in a poor urban neighborhood in Cairo, Egypt: Maternal beliefs and perceptions. Soc Sci Med 36, 1063-1069.

Harrison GG \& Jerome NW (1992) Diet during lactation associated with infant behavior and caregiver interaction in a semirural Egyptian village. $J$ Nutr 123, 164-175.

Hubley J (1993) Communicating Health: An Action Guide to Health Education and Health Promotion. London: Macmillan Press.

Iranian Health Ministry (1996) Education Packages for Intervention Programs for Reducing Children's Malnutrition. Tehran: Nour Publishing Company.

Iranian Health Ministry (2001) Survey of the pattern of Food and Nutrition Security Program. First Report. Tehran: Nour Publishing Company.

Iranian Health Ministry (2002) Survey of the pattern of Food and Nutrition Security Program. Second Report. Tehran: Nour Publishing Company.

Launer LJ \& Habicht J-P (1989) Concepts about infant health, growth, and weaning: A comparison between nutritional scientists and Madurese mothers. Soc Sci Med 29, 13-22.

McKee N (2002) Advocacy and Public Awareness Lesson for the Communicator. www.southside.org.sg

Movahedi A (2000) Iranian Food Composition Tables. Tehran: National Nutrition and Food Technology Research Institute Press.

Politt E, Gorman KS, Engle PL, Martorell R \& Rivera J (1993) Early supplementary feeding and cognition. Monogr Soc Res Child Dev 58, 1-99.

Rabiee F \& Geissler C (1992) The impact of maternal work load on child nutrition in rural Iran. Food Nutr Bull 14, 43-48.

Reinhard I \& Kramer D (1999) Baseline Survey on Health and Nutrition Working Paper. Malnutrition for Different Ethnic Groups in Trincomalee District (24 November 1999) http://www.ifspsrilanka.org/html/wp_24_baseline_survey_health_a.html

Reissland N \& Burghart R (1988) The quality of a mother's milk and the health of the child: Beliefs and practices of the women of Mithila. Soc Sci Med 27, 461-469.

Sahn DE, Lockwood R \& Scrimshaw NS (1981) Methods for Evaluation of the Impact of Food and Nutrition Programs. Report of a Workshop on the Evaluation of Food Nutrition Programs. Cambridge, MA: MIT Press.

Salehi M \& Kalantari-Rahmani N (1999) A Study of Food and Nutrients in Qashqa'i Tribes. Tehran: Iranian Food and Nutrients Institute.

Salehi M \& Neghab M (2001) Evaluation of the impact of weaning food messages on infant feeding practices and child growth in Iranian tribes. In 7th Iranian Nutrition Congress, September 2-5. Abstr. Ahvag, Iran: Chamran University Press.

Shahbazi M (1998) Formal education, schoolteachers and ethnic 
identity among the Qashqa'i of Iran, $\mathrm{PhD}$ Thesis: Washington University.

US Agency for International Development (1988) Growth Monitoring and Nutrition Education. Washington, DC: American Public Health Association.

Zeitlin M (1981) Upper Volta Case Study of Home Based Community Level Weaning: Food Development Study IV for Mutated Foods. Cambridge, MA: US Agency for International Development.

Zeitlin M, Griffith SM \& Manoff R (1984) Household Evaluation, Nutrition Communication and Behavior Change Component. Indonesian Nutrition Development program, vol. 4, New York: Monoff International Inc.

\section{Appendix}

\section{Education programme steps}

(1) Tools and methods in educational design: books, films, posters, manuscripts, speeches, work groups, face-to-face education and training in practical skills.

(2) Education team in the first phase: authors, health education and family planning experts employed in the Health Centre of Fars Province.

(3) First target population: assistants (literate volunteering tribal females acting as communicators of health matters to the tribe) and tribal teachers.

(4) Education teams in the second phase: authors, health education and family planning experts employed in the Health Centre of Fars Province as well as the first target population described in (3).

(5) Final target population: parents of children $<5$ years old and others acting as caregivers.
Educational programme content

(1) Environmental health (inside and outside tents).

(2) Sanitary waste disposal.

(3) Personal hygiene (particularly concerning mother and child).

(4) Water supply and sanitation.

(5) Knowledge about the proper use of child vaccination charts.

(6) Knowledge about the proper use of child growth charts.

(7) Explanation of the concepts 'food pyramid' and 'food groups'.

(8) Requirements for meat, milk and yoghurt, cheese and dried whey, and their preservation and storage.

(9) Baking method for fermented bread.

(10) Cooking method for rice (straining and cooking over a low fire, adding pulses or herbs).

(11) Increased use of pulses in the daily diet (lentil porridge, lentil meal in soups, beans).

(12) Ways of gaining access to fruits and vegetables, proper washing and education about the necessity of their daily consumption.

(13) Butter and oil, consumption with regard to age and amount of physical activity, discussion of fried foods.

(14) Food and nutrition during pregnancy and lactation.

(15) Supplementation of drugs, vitamins and minerals.

(16) Complementary foods and consumption of solid foods by 1 -year-old children.

(17) Attention to children's diet after weaning until school age.

(18) Prompt referral of mother and child to the nearest available health centre upon observing the first signs of weakness, disorder or disease. 